\title{
Laminar natural convection from a vertical array of horizontal heated cylinders inside a water-filled rectangular enclosure cooled at sides
}

A water-filled rectangular enclosure

\author{
Marta Cianfrini
}

DIMI, Università degli Studi Roma Tre, Rome, Italy

Massimo Corcione

DIAEE, Sapienza Università di Roma, Rome, Italy

Alessandro Quintino

DIAEE, Sezione Fisica Tecnica, Sapienza Università di Roma, Rome, Italy, and

\author{
Vincenzo Andrea Spena \\ DIAEE, Sapienza Università di Roma, Rome, Italy
}

\begin{abstract}
Purpose - The purpose of this study is to investigate numerically the laminar natural convection from a pair of horizontal heated cylinders, set one above the other, inside a water-filled rectangular enclosure cooled at sides, with perfectly insulated top and bottom walls, through a control-volume formulation of the finite-difference method, with the main aim to evaluate the effects of the center-to-center cylinder spacing, the size of the cavity and the temperature difference imposed between the cylinders and the cavity sides.

Design/methodology/approach - The system of the conservation equations of the mass, momentum and energy, expressed in dimensionless form, is solved by a specifically developed computer code based on the SIMPLE-C algorithm for the pressure-velocity coupling. Numerical simulations are executed for different values of the Rayleigh number based on the cylinder diameter, as well as the center-to-center cylinder spacing and the width of the cavity normalized by the cylinder diameter.

Findings - The main results obtained may be summarized as follows: the existence of an optimum cylinder spacing for maximum heat transfer rate is found at any investigated Rayleigh number; as a consequence of the downstream confinement, a periodic flow arises at sufficiently high Rayleigh numbers; the amplitude of oscillation of the periodic heat transfer performance of the cylinder array decreases as the cylinder spacing is increased and the cavity width is decreased, whereas the frequency of oscillations remains almost the same; at very small cavity widths, a transition from the typical twocell to a four-cell flow pattern occurs.
\end{abstract}

Originality/value - The computational code used in the present study incorporates an original composite polar/Cartesian discretization grid scheme.

Keywords Numerical analysis, Natural convection, Periodic flow, Vertical cylinder array, Water-filled enclosure

Paper type Research paper
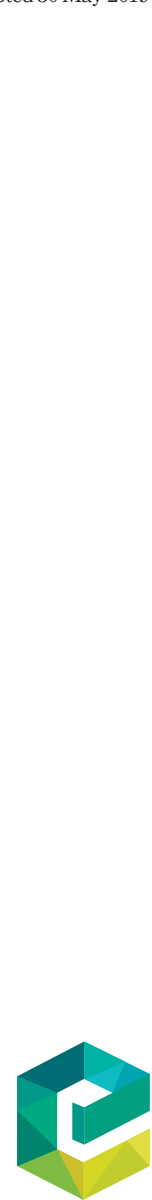
$\mathrm{HFF}$

30,5

\section{Nomenclature}

$\mathrm{D}=$ cylinder diameter, $\mathrm{m}$;

g = gravity vector, $\mathrm{m} / \mathrm{s}^{2}$;

$\mathrm{g}=$ gravitational acceleration, $\mathrm{m} / \mathrm{s}^{2}$;

$\mathrm{H}=$ height of the cavity, $\mathrm{m}$;

$\mathrm{L}$ = distance of the axis of the bottom cylinder from the bottom wall of the cavity, m;

$\mathrm{N}$ = number of cylinders;

$\mathrm{Nu}=$ Nusselt number;

$\mathrm{P}=$ dimensionless pressure;

$\operatorname{Pr}=$ Prandtl number;

$\mathrm{R}=$ cylinder radius, $\mathrm{m}$;

$\mathrm{r}$ = radial coordinate;

Ra = Rayleigh number;

$\mathrm{S}$ = center-to-center cylinder spacing, $\mathrm{m}$;

$\mathrm{T}=$ dimensionless temperature;

$\mathrm{t} \quad=$ temperature, $\mathrm{K}$;

$\mathrm{V}=$ dimensionless velocity vector;

$\mathrm{W}$ = width of the cavity, $\mathrm{m}$.

\section{Greek symbols}

$\alpha=$ thermal diffusivity, $\mathrm{m}^{2} / \mathrm{s}$;

$\beta=$ coefficient of volumetric thermal expansion, $1 / \mathrm{K}$;

$\theta=$ angular coordinate;

$\nu=$ kinematic viscosity, $\mathrm{m}^{2} / \mathrm{s}$;

$\rho=$ mass density, $\mathrm{kg} / \mathrm{m}^{3}$;

$\tau=$ dimensionless time.

\section{Subscripts}

c = cooled sidewalls;

$\mathrm{h}=$ heated cylinders.

\section{Introduction}

Natural convection from vertical arrays of heated horizontal cylinders has been widely investigated in the past decades, both numerically and, above all, experimentally, because of its considerable relevance to many thermal engineering applications, such as heat exchangers and energy storage devices.

Although the main body of the research performed on this topic has been executed using air as working fluid - for example, Marsters, 1972; Sparrow and Niethammer, 1981; Tokura et al., 1983; and Sadegh Sadeghipour and Asheghi, 1994 - a number of studies recently carried out for liquids are also available in the literature. A summary of these publications is presented in Table I (Reymond et al., 2008; Persoons et al., 2011; Chae and Chung, 2011; Grafsrønningen and Jensen, 2012; Heo et al., 2013; Grafsrønningen and Jensen, 2013; Shyam et al., 2013; Heo and Chung, 2014), in which indications on the research approach, the type of liquid, the examined ranges/values of the number of cylinders, the center-to-center separation distance between the cylinders and the Rayleigh number based on the cylinder diameter are enumerated. 
The main common findings of most works indicate that the heat transfer rate at the bottom cylinder is substantially unaffected by the presence of the top cylinder, whereas the top cylinder exhibits reduced heat transfer rates at close spacings and enhanced heat transfer rates at large spacings, as a direct consequence of the two opposite effects originating from the warm plume spawned by the bottom cylinder. In fact, the hot buoyant flow induced by the bottom cylinder acts as a forced convection field wherein the top cylinder is embedded, and causes a decrease in the temperature difference between the surface of the top cylinder and the adjacent fluid. The first effect, which tends to increase the heat transfer performance of the top cylinder, prevails at large spacings, whereas the second effect, which tends to degrade the heat transfer performance of the top cylinder, is of major importance at close spacings. Actually, this can be easily explained using the theoretical results obtained by Gebhart et al., 1970, who demonstrated that for a plume generated by a horizontal line source, the centerline velocity increases as the fifth power of the distance above the source, whereas the centerline temperature decreases as the inverse of the three-fifths power of the distance, which implies that from a given distance onward, the velocity effect has to outweigh the increased fluid temperature effect. Indeed, the experiments conducted using water pointed out the existence of an optimum cylinder spacing at which the amount of heat transferred by the top cylinder has a peak. Additionally, a periodicity in the heat transfer rate at the top cylinder was also detected because of the plume oscillation consequent to its downstream confinement, as found experimentally by Incropera and Yaghoubi, 1980; Atmane et al., 2003; and Kuehner et al., 2012 for a submerged cylinder, and by Fiscaletti et al., 2013 for a cylinder suspended inside a closed cavity cooled at the walls.

However, despite the main phenomenological aspects of the problem being well understood, few data are available for top confinements obtained using solid walls rather than a free surface, and for Rayleigh numbers lower than $10^{6}$, especially considering that Shyam et al. (2013) focused their attention principally on the behavior of non-Newtonian liquids. Moreover, the effects of possible side confinements seem to have never been taken into full account.

All these considerations motivated us to carry out the present study, in which natural convection from a pair of heated horizontal cylinders set one above the other in a water-filled rectangular enclosure, with the sidewalls cooled and the top and bottom walls perfectly insulated, is investigated numerically through a control-volume formulation of the finitedifference method. The main scope of this paper is to evaluate in what measure the center-tocenter cylinder spacing, the size of the cavity and the temperature difference imposed between the cylinders and the cavity sides affect the overall heat transfer performance, and to discuss the basic heat and fluid flow features.

\begin{tabular}{lllllcc}
\hline Year & Author(s) & Method & Liquid & $N$ & $\mathrm{~S} / \mathrm{D}$ & $\operatorname{Ra}_{\mathrm{D}}$ \\
\hline 2008 & Reymond et al. (2008) & Exp & Water & 2 & $1.5-3$ & $2 \times 10^{6}-6 \times 10^{6}$ \\
2011 & Persoons et al. (2011) & Exp & Water & 2 & $2-4$ & $1.8 \times 10^{6}-5.5 \times 10^{6}$ \\
2011 & Chae and Chung (2011) & Exp/num & Pr $=2014-8334$ & 2 & $1.02-9$ & $7.3 \times 10^{7}-4.5 \times 10^{10}$ \\
2012 & Grafsrønningen and Jensen (2012) & Exp & Water & 2 & $1.5-5$ & $1.82 \times 10^{7}-2.55 \times 10^{8}$ \\
2013 & Heo et al., 2013) & Exp/num & Pr $=5-2014$ & 2 & $1.1-5.4$ & $1.5 \times 10^{8}-2.5 \times 10^{10}$ \\
2013 & Grafsrønningen and Jensen (2013) & Exp & Water & 3 & $2-5$ & $1.96 \times 10^{7}-5.35 \times 10^{7}$ \\
2013 & Shyam et al. (2013) & Num & $\operatorname{Pr}=10-100$ & 2 & $2-20$ & $7.2-10^{6}$ \\
2014 & Heo and Chung (2014) & Num & $\operatorname{Pr}=5-2014$ & 2 & $1.1-5.4$ & $1.5 \times 10^{8}$
\end{tabular}

A water-filled rectangular enclosure

2609

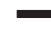


HFF

30,5

\section{0}

\section{Mathematical formulation}

A water-filled rectangular enclosure of width $\mathrm{W}$ and height $\mathrm{H}$, containing a vertical array of two horizontal cylinders of radius $\mathrm{R}$, is considered. The cylinders, set at a center-to-center spacing $\mathrm{S}$, are suspended in the vertical midplane of the cavity at an elevation identified by the distance $\mathrm{L}$ of the axis of the bottom cylinder from the bottom wall of the enclosure. Both cylinders are heated at a uniform temperature $t_{h}$, while the sidewalls of the cavity are cooled at a uniform temperature $t_{c}$, the remaining top and bottom walls being perfectly insulated, as sketched in Figure 1. The resulting buoyancy-induced flow is considered to be twodimensional, laminar and incompressible, respectively, with constant physical properties. The buoyancy effects on the momentum transfer are taken into account through the customary Boussinesq approximation. Viscous dissipation and pressure work, as well as radiative heat transfer, are neglected.

Upon incorporating these hypotheses into the conservation equations of the mass, momentum and energy, the following set of governing equations expressed in dimensionless form are obtained:

$$
\begin{gathered}
\nabla \cdot \mathbf{V}=0 \\
\frac{\partial \mathbf{V}}{\partial \tau}+(\mathbf{V} \cdot \nabla) \mathbf{V}=-\nabla \mathrm{P}+\nabla^{2} \mathbf{V}-\frac{\operatorname{Ra}}{\operatorname{Pr}} \mathrm{T} \frac{\mathbf{g}}{\mathrm{g}} \\
\frac{\partial T}{\partial \tau}+(\mathbf{V} \cdot \nabla) \mathrm{T}=\frac{1}{\operatorname{Pr}} \nabla^{2} \mathrm{~T}
\end{gathered}
$$

where $\tau$ is the dimensionless time normalized by $\mathrm{D}^{2} / \nu, \mathbf{V}$ is the dimensionless velocity vector normalized by $\nu / \mathrm{D}$, T is the dimensionless temperature excess over the uniform temperature of the cavity sidewalls normalized by the temperature difference $\left(t_{h}-t_{c}\right), P$ is the dimensionless sum of the thermodynamic and hydrostatic pressures normalized by $\rho \nu^{2} / \mathrm{D}^{2}, \mathbf{g}$ is the gravity vector, $\mathrm{g}$ is the gravity acceleration, $\operatorname{Pr}=\nu / \alpha$ is the Prandtl number set to 7 (corresponding to water at a temperature of $293 \mathrm{~K}$ ) and Ra is the Rayleigh number defined as:

Figure 1.

Sketch of the geometry and boundary conditions

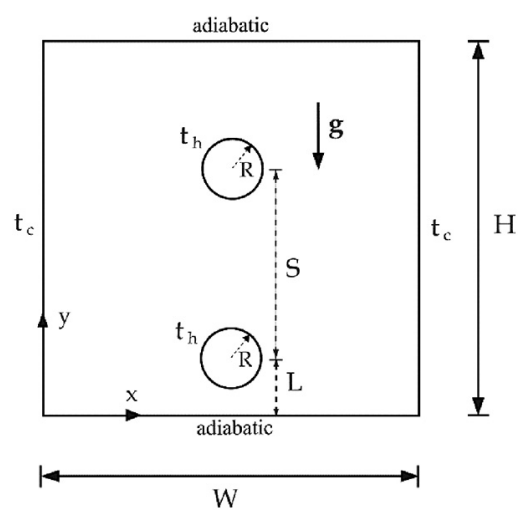




$$
\mathrm{Ra}=\frac{\mathrm{g} \beta\left(\mathrm{t}_{\mathrm{h}}-\mathrm{t}_{\mathrm{c}}\right) \mathrm{D}^{3}}{\alpha \nu}
$$

in which $\mathrm{D}=2 \mathrm{R}$ is the cylinder diameter, $\nu$ is the kinematic viscosity, $\rho$ is the mass density, $\alpha$ is the thermal diffusivity and $\beta$ is the coefficient of volumetric thermal expansion.

The assigned boundary conditions are:

- $\mathrm{T}=1$ and $\mathbf{V}=0$ at the surface of the heated cylinders.

- $\mathrm{T}=0$ and $\mathrm{V}=0$ at both sidewalls.

- $\partial \mathrm{T} / \partial \mathrm{Y}=0$ and $\mathbf{V}=0$ at the top and bottom walls, where $\mathrm{Y}$ is the dimensionless vertical Cartesian coordinate normalized by $\mathrm{D}$.

The initial conditions assumed throughout the enclosure are fluid at rest, i.e. $\mathbf{V}=0$ and uniform temperature $\mathrm{T}=0$.

\section{Computational procedure}

The system of the governing equations defined from equations (1) to (3), in combination with the boundary and initial conditions stated earlier, is solved through a control-volume formulation of the finite-difference method. The pressure--velocity coupling is handled using the SIMPLE-C algorithm introduced by Van Doormaal and Raithby, 1984, which is essentially a more implicit variant of the SIMPLE algorithm developed by Patankar and Spalding, 1972. The convective terms are approximated through the QUICK discretization scheme proposed by Leonard, 1979, whereas, a second-order backward scheme is applied for time integration. According to the geometry of the system, a cylindrical polar grid is fixed around each cylinder, while a Cartesian grid is used to fill the remainder of the integration domain. The polar and Cartesian grids, which are entirely independent of one another, overlap with no attempt of node-matching, their connection being provided by a row of false nodes, in which the values of the dependent variables are calculated by a linear interpolation of their values at the four surrounding real nodes, as discussed in (Corcione, 2005). Nonuniform structured grids are used for the discretization of both the polar and the Cartesian grid regions, having a higher concentration of grid nodes near the boundary surfaces and a relatively lower uniform spacing throughout the remainder interior of the cavity. Conversely, time discretization is chosen uniformly.

Starting from the assigned initial fields of the dependent variables, at each time-step, the system of the discretized algebraic governing equations is solved iteratively by the way of a line-by-line application of the Thomas algorithm. A standard under-relaxation technique is enforced in all the steps of the computational procedure to ensure an adequate convergence. Within each time-step, the spatial numerical solution of the velocity and temperature fields is considered to be converged when the maximum absolute value of the mass source, as well as the relative changes of the dependent variables at any grid-node between two consecutive iterations, is smaller than the pre-specified values of $10^{-6}$ and $10^{-7}$, respectively. As time passes, the dynamic behavior of the system is followed by plotting the phase-space trajectories of the dependent variables at some assigned grid nodes, i.e. by plotting the distributions of the local time-derivatives of the dependent variables vs the variables themselves with time as a parameter, whose attractor may be represented by either a fixed point, a limit cycle, a torus or a so-called strange attractor, to visualize the tendency of the system to reach either a steady-state, a periodic, a quasi-periodic or a chaotic solution. In addition, the time-distributions of the incoming and outgoing heat transfer rates, as well as 
their relative difference, are continuously monitored to assess the achievement of an asymptotic solution.

At each time-step, after the spatial convergence is adequately attained, the local Nusselt number of the $\mathrm{i}$-th cylinder, $\left[\mathrm{Nu}_{\theta}(\tau)\right]$; , where subscripts 1 and 2 denote the bottom and the top cylinders, respectively, is calculated as:

$$
\left[\mathrm{Nu}_{\theta}(\tau)\right]_{i}=-\left[\left.\frac{\partial \mathrm{T}(\tau)}{\partial \mathrm{r}}\right|_{\mathrm{R}, \theta}\right]_{\mathrm{i}}, \quad(\mathrm{i}=1,2)
$$

in which, the $\mathrm{r}$ and $\theta$ coordinates of the polar reference system are measured from the center of the cylinder, and anticlockwise from downwards, respectively, and the temperature gradient is evaluated by a second-order temperature profile embracing the wall-node and the two adjacent fluid-nodes.

Hence, the corresponding average Nusselt number of the i-th cylinder at time $\tau,[\mathrm{Nu}(\tau)]_{\mathrm{i}}$, is calculated with the expression:

$$
[\mathrm{Nu}(\tau)]_{i}=\frac{1}{2 \pi}\left[\int_{0}^{2 \pi}-\left.\frac{\partial \mathrm{T}(\tau)}{\partial \mathrm{r}}\right|_{\mathrm{R}, \theta} \mathrm{d} \theta\right]_{\mathrm{i}}, \quad(\mathrm{i}=1,2)
$$

the integral being computed numerically by means of the trapezoidal rule.

Time integration is stopped once an asymptotic solution, either stationary or periodic, is reached. When a steady-state solution is achieved, the Nusselt number of the i-th cylinder coincides with the last value computed for $[\mathrm{Nu}(\tau)]_{\mathrm{i}}$ :

$$
\mathrm{Nu}_{i}=\left.[\mathrm{Nu}(\tau)]_{i}\right|_{\tau \rightarrow \infty} . \quad(\mathrm{i}=1,2)
$$

Conversely, when a periodic solution is attained, the Nusselt number $\mathrm{Nu}_{\mathrm{i}}$ is evaluated as:

$$
\mathrm{Nu}_{i}=\frac{1}{\Omega} \int_{0}^{\Omega}[\mathrm{Nu}(\tau)]_{\mathrm{i}} \mathrm{d} \tau . \quad(\mathrm{i}=1,2)
$$

where $\Omega$ is the dimensionless period of oscillation computed by the solution algorithm.

The heat transfer performance of the whole array is then calculated as the arithmetic mean of the average Nusselt numbers of both cylinders, i.e.:

$$
\mathrm{Nu}=\frac{\mathrm{Nu}_{1}+\mathrm{Nu}_{2}}{2}
$$

Numerical tests on the dependence of the results on the mesh spacing and time stepping have been methodically performed for several combinations of the three controlling parameters, namely, $\mathrm{Ra}, \mathrm{S} / \mathrm{D}$ and $\mathrm{W} / \mathrm{D}$, imposing $\mathrm{L} / \mathrm{D}=1.5$ and $\mathrm{H} / \mathrm{D}=10$. Accordingly, the discretization grids and time-steps used for computations are chosen in such a way that 
further refinements do not produce noticeable modifications either in the heat transfer rates or in the flow fields, with percentage changes smaller than the pre-established accuracy of 1 per cent. The typical number of nodal points of the polar and Cartesian discretization grids used for simulations lie in the ranges between $80 \times 80$ and $100 \times 100$ and between $100 \times 100$ and $140 \times 140$, respectively. Moreover, typical dimensionless time-steps used for simulations lie in the range between $10^{-4}$ and $10^{-3}$. Selected results of the grid-size and time-stepping sensitivity analysis are presented in Tables II and III.

Finally, with the aim to validate the numerical code and the composite-grid discretization scheme used in the present study, four tests have been carried out. In the first test, the local and average Nusselt numbers computed at several Rayleigh numbers for a single cylinder suspended in air have been compared with the corresponding benchmark numerical data of Saitoh et al., 1993, as shown in Table IV, where the numerical results of Wang et al., 1990, and Kuehn and Goldstein, 1980, are also reported for further comparison. In the second test, the average Nusselt numbers computed at several Rayleigh numbers for a single cylinder suspended in water have been compared with the data obtained using two of the most prominent correlations for free convection heat transfer from a single cylinder available in the literature, i.e. those by Raithby and Hollands, 1976, and Kuehn and Goldstein, 1976, as shown in Table V. In the third test, a comparison is carried out with the experimental data published by Sparrow and Niethammer, 1981; Tokura et al., 1983; and Sparrow and Boessneck, 1983, for a two-cylinder vertical array suspended in air, as displayed in Tables VI, VII and VIII, respectively, in which the average Nusselt number of any individual cylinder or the whole array is normalized by the average Nusselt number $\mathrm{Nu}_{0}$ of the single

\begin{tabular}{|c|c|c|c|c|c|c|c|}
\hline $\mathrm{Ra}$ & $\mathrm{W} / \mathrm{D}$ & $\mathrm{S} / \mathrm{D}$ & Cartesian mesh size & Polar mesh size & $\mathrm{Nu}$ & $(\%)$ & \\
\hline \multirow[t]{4}{*}{$10^{4}$} & 5 & 3 & $60 \times 60$ & $35 \times 70$ & 4.305 & - & \\
\hline & & & $80 \times 80$ & $40 \times 80$ & 4.236 & -1.61 & \\
\hline & & & $100 \times 100$ & $45 \times 90$ & 4.181 & -1.30 & \\
\hline & & & $120 \times 120$ & $50 \times 100$ & 4.173 & -0.18 & \\
\hline \multirow{4}{*}{$10^{4}$} & 5 & 5 & $60 \times 60$ & $35 \times 70$ & 4.256 & - & \\
\hline & & & $80 \times 80$ & $40 \times 80$ & 4.178 & -1.83 & \\
\hline & & & $100 \times 100$ & $45 \times 90$ & 4.132 & -1.10 & \\
\hline & & & $120 \times 120$ & $50 \times 100$ & 4.112 & -0.48 & \\
\hline \multirow[t]{4}{*}{$10^{4}$} & 10 & 5 & $60 \times 60$ & $35 \times 70$ & 4.214 & - & \\
\hline & & & $80 \times 80$ & $40 \times 80$ & 4.148 & -1.57 & \\
\hline & & & $100 \times 100$ & $45 \times 90$ & 4.093 & -1.33 & \\
\hline & & & $120 \times 120$ & $50 \times 100$ & 4.086 & -0.17 & \\
\hline \multirow[t]{4}{*}{$10^{6}$} & 10 & 5 & $80 \times 80$ & $35 \times 70$ & 14.910 & - & Table II. \\
\hline & & & $100 \times 100$ & $40 \times 80$ & 14.586 & -2.17 & Grid sensitivity \\
\hline & & & $120 \times 120$ & $45 \times 90$ & 14.315 & -1.86 & analysis for $\Delta \tau=$ \\
\hline & & & $140 \times 140$ & $50 \times 100$ & 14.250 & -0.45 & $10^{-4}$ \\
\hline
\end{tabular}

A water-filled rectangular enclosure

2613

\begin{tabular}{|c|c|c|c|c|c|c|c|c|}
\hline Cartesian mesh size & Polar mesh size & $\mathrm{Ra}$ & W/D & $\mathrm{S} / \mathrm{D}$ & $\Delta \tau$ & $\mathrm{Nu}$ & $(\%)$ & Table III. \\
\hline $120 \times 120$ & $50 \times 100$ & $10^{4}$ & 10 & 5 & $\begin{array}{l}1 \times 10^{-3} \\
5 \times 10^{-4} \\
1 \times 10^{-4} \\
5 \times 10^{-5}\end{array}$ & $\begin{array}{l}4.231 \\
4.143 \\
4.086 \\
4.081\end{array}$ & $\begin{array}{c}- \\
-2.08 \\
-1.38 \\
-0.12\end{array}$ & $\begin{array}{r}\text { Time-step sensitivity } \\
\text { analysis for Ra }=10^{4}, \\
\mathrm{~S} / \mathrm{D}=5 \text { and } \mathrm{W} / \\
\mathrm{D}=10\end{array}$ \\
\hline
\end{tabular}




\section{$\mathrm{HFF}$}

30,5

\section{4}

Table IV.

Comparison of the present solutions for the local and average Nusselt numbers of a single cylinder suspended in air and the corresponding data of Saitoh et al., (1993); Wang et al., (1990) and Kuehn and Goldstein, (1980)

\begin{tabular}{lcccccccc}
\hline & $\begin{array}{c}\mathrm{Nu}(\theta) \\
\theta=0^{\circ}\end{array}$ & $30^{\circ}$ & $60^{\circ}$ & $90^{\circ}$ & $120^{\circ}$ & $150^{\circ}$ & $180^{\circ}$ & $\mathrm{Nu}$ \\
\hline Ra & & & & & & & & \\
\hline $10^{3}$ & 3.789 & 3.755 & 3.640 & 3.376 & 2.841 & 1.958 & 1.210 & 3.013 \\
Present & 3.813 & 3.772 & 3.640 & 3.374 & 2.866 & 1.975 & 1.218 & 3.024 \\
Saitoh et al. (1993) & 3.860 & 3.820 & 3.700 & 3.450 & 2.930 & 1.980 & 1.200 & 3.060 \\
Wang et al. (1990) & 3.890 & 3.850 & 3.720 & 3.450 & 2.930 & 2.010 & 1.220 & 3.030 \\
Kuehn and Goldstein (1980) & & & & & & & & \\
$10^{4}$ & & & & & & & & \\
Present & 5.986 & 5.931 & 5.756 & 5.406 & 4.716 & 3.293 & 1.532 & 4.819 \\
Saitoh et al. (1993) & 5.995 & 5.935 & 5.750 & 5.410 & 4.764 & 3.308 & 1.534 & 4.826 \\
Wang et al. (1990) & 6.030 & 5.980 & 5.800 & 5.560 & 4.870 & 3.320 & 1.500 & 4.860 \\
Kuehn and Goldstein (1980) & 6.240 & 6.190 & 6.010 & 5.640 & 4.820 & 3.140 & 1.460 & 4.940 \\
10 & & & & & & & & \\
Present & 9.694 & 9.595 & 9.297 & 8.749 & 7.871 & 5.848 & 1.989 & 7.886 \\
Saitoh et al. (1993) & 9.675 & 9.577 & 9.278 & 8.765 & 7.946 & 5.891 & 1.987 & 7.898 \\
Wang et al. (1990) & 9.800 & 9.690 & 9.480 & 8.900 & 8.000 & 5.800 & 1.940 & 7.970 \\
Kuehn and Goldstein (1980) & 10.15 & 10.03 & 9.650 & 9.020 & 7.910 & 5.290 & 1.720 & 8.000 \\
\hline & & & & & & & &
\end{tabular}

\section{Table V.}

Comparison of the present solutions for the average Nusselt number and the corresponding data derived from the correlations of Raithby and Hollands (1976) and Kuehn and Goldstein (1980)

\begin{tabular}{lcccccc}
\hline & & \multicolumn{5}{c}{$\mathrm{Nu}$} \\
& $\mathrm{Ra}=10^{2}$ & $10^{3}$ & $10^{4}$ & $10^{5}$ & $10^{6}$ & $10^{7}$ \\
\hline Present & 2.340 & 3.450 & 5.700 & 9.240 & 15.889 & 18.713 \\
Raithby and Hollands (1976) & 2.347 & 3.552 & 5.645 & 9.330 & 15.856 & 18.674 \\
Kuehn and Goldstein (1976) & 2.369 & 3.589 & 5.711 & 9.445 & 16.062 & 18.923 \\
\hline
\end{tabular}

\section{Table VI.}

Comparison of the present solutions for the average Nusselt number of the top cylinder in a 2-cylinder vertical array suspended in air with the experimental results of Sparrow and Niethammer (1981)

\begin{tabular}{lccc}
\hline $\mathrm{S} / \mathrm{D}=2$ & $\mathrm{Ra}=2 \times 10^{4}$ & $\mathrm{Nu}_{2} / \mathrm{Nu}_{0}$ \\
$6 \times 10^{4}$ & $10^{5}$ \\
\hline Present & 0.810 & 0.844 & 0.856 \\
Sparrow and Niethammer (1981) & 0.820 & 0.850 & 0.860 \\
\hline
\end{tabular}


cylinder. In the fourth test, the results obtained for the top cylinder of a two-cylinder vertical array, suspended in water are compared with the experimental data reported by Reymond et al., 2008, for $\mathrm{Ra}=2 \times 10^{6}$ and $\mathrm{S} / \mathrm{D}=3$, as depicted in Figure 2 . It is apparent that in any validation test carried out, a satisfactorily good degree of agreement between our numerical results and the literature data has been achieved.

\section{Results and discussion}

Numerical simulations are performed for $\operatorname{Pr}=7$, which corresponds to water, and for different values of (a) the Rayleigh number $\mathrm{Ra}$ in the range between $10^{3}$ and $10^{7}$, (b) the dimensionless center-to-center cylinder spacing S/D in the range between 1.25 and 7 and (c) the dimensionless cavity width W/D in the range between 1.05 and 15 . As regards the dimensionless distance of the axis of the bottom cylinder from the bottom wall, $\mathrm{L} / \mathrm{D}$, and the dimensionless cavity height, $\mathrm{H} / \mathrm{D}$, all the simulations have been executed assuming $\mathrm{L} /$ $\mathrm{D}=1.5$ and $\mathrm{H} / \mathrm{D}=10$.

Typical local results are reported in Figures 3 and 4, in which steady-state streamline and isotherm contours, relative to three different cylinder spacings, are plotted for $\mathrm{Ra}=10^{5}$ and $\mathrm{W} / \mathrm{D}=10$. It is apparent that the flow structure consists of two counter-rotating, kidneyshaped cells originating from the rise of the hot fluid above both heated cylinders and the fall of two streams of cold fluid along the cooled sidewalls. Correspondingly, the temperature distribution is featured by a thermal plume emerging from the top of the cylinders, two boundary layers adjacent to the sidewalls and a pair of stratified regions located between the cylinders and the sidewalls. The related distribution of the average Nusselt number of the cylinder array, $\mathrm{Nu}$, is depicted in Figure 5.

As expected, the inter-cylinder spacing has been found to have a negligible effect on the heat transfer rate at the bottom cylinder, which tends to behave as a single cylinder,

\begin{tabular}{llcccr}
\hline & & \multicolumn{4}{c}{$\mathrm{Nu}_{\mathrm{Nu}}$} \\
$\mathrm{Ra}=8.5 \times 10^{4}$ & & $\mathrm{~L} / \mathrm{D}=1.1$ & 1.3 & 1.5 & 2 \\
\hline Bottom cylinder & Present & 0.908 & 0.965 & 0.996 & 1.008 \\
& Tokura et al. (1983) & 0.890 & 0.940 & 1.000 & 1.010 \\
Top cylinder & Present & 0.614 & 0.661 & 0.726 & 0.853 \\
& Tokura et al. (1983) & 0.610 & 0.680 & 0.740 & 0.870 \\
Whole array & Present & 0.761 & 0.813 & 0.861 & 0.930 \\
& Tokura et al. (1983) & 0.750 & 0.810 & 0.870 & 0.940 \\
& & & &
\end{tabular}

\begin{tabular}{lccr}
\hline & & & $\mathrm{Nu} / \mathrm{Nu}_{0}$ \\
$\mathrm{Ra}$ & $\mathrm{S} / \mathrm{D}$ & Sparrow and Boessneck (1983) & Present \\
\hline $6 \times 10^{4}$ & 2.0 & 3.755 & 3.640 \\
& 5.0 & 3.850 & 3.720 \\
$1 \times 10^{5}$ & 2.0 & 5.931 & 5.756 \\
& 5.0 & 6.190 & 6.010 \\
$2 \times 10^{5}$ & 2.0 & 9.595 & 9.297 \\
& 5.0 & 10.03 & 9.650
\end{tabular}

A water-filled rectangular enclosure

2615

Table VII.

Comparison of the present solutions for the average Nusselt number of any individual cylinder in a 2-cylinder vertical array suspended in air with the experimental results of Tokura et al. [3]

Table VIII.

Comparison of the present solutions for the average Nusselt number of the top cylinder in a 2-

cylinder vertical array suspended in air with the experimental results of Sparrow and Boessneck (1983) 
HFF

30,5

\section{6}

Figure 2.

Comparison of the present solutions for the average Nusselt number of the top cylinder of a 2-cylinder vertical array suspended in water and the experimental results of Reymond et al., 2008

Figure 3.

Steady-state streamline contours for $\mathrm{Ra}=10^{5}$, $\mathrm{W} / \mathrm{D}=10$ and $\mathrm{S} / \mathrm{D}=2.5,4$ and 7

\section{Figure 4.}

Steady-state isotherm contours for $\mathrm{Ra}=$ $10^{5}, \mathrm{~W} / \mathrm{D}=10$ and $\mathrm{S} / \mathrm{D}=2.5,4$ and 7 provided that $\mathrm{S} / \mathrm{D}$ is not so small to give rise to a widening of the rear stagnation region with a consequent degradation of the heat transfer performance. Conversely, the inter-cylinder spacing has more significant effects on the heat transfer rate at the top cylinder, thus affecting the heat transfer performance of the whole array. As a matter of fact, the increase of the inter-cylinder spacing tends to enhance the heat transfer rate at the top cylinder surface because of the larger beneficial velocity effect being compared with the unfavorable increased temperature effect, but, at the same time, the corresponding decrease of the distance of the top cylinder from the top wall of the cavity results in a decrease of the motion intensity, which tends to reduce the heat transfer rate, thus explaining the existence of an optimum cylinder spacing for maximum heat transfer.

Different heat and fluid flow configurations are found at higher Rayleigh numbers, at which the asymptotic solution may become periodic, as shown in Figure 6, where the asymptotic time-distributions of $\mathrm{Nu}_{1}, \mathrm{Nu}_{2}$ and $\mathrm{Nu}$ are reported for $\mathrm{Ra}=2 \times 10^{6}, \mathrm{~S} / \mathrm{D}=4$ and
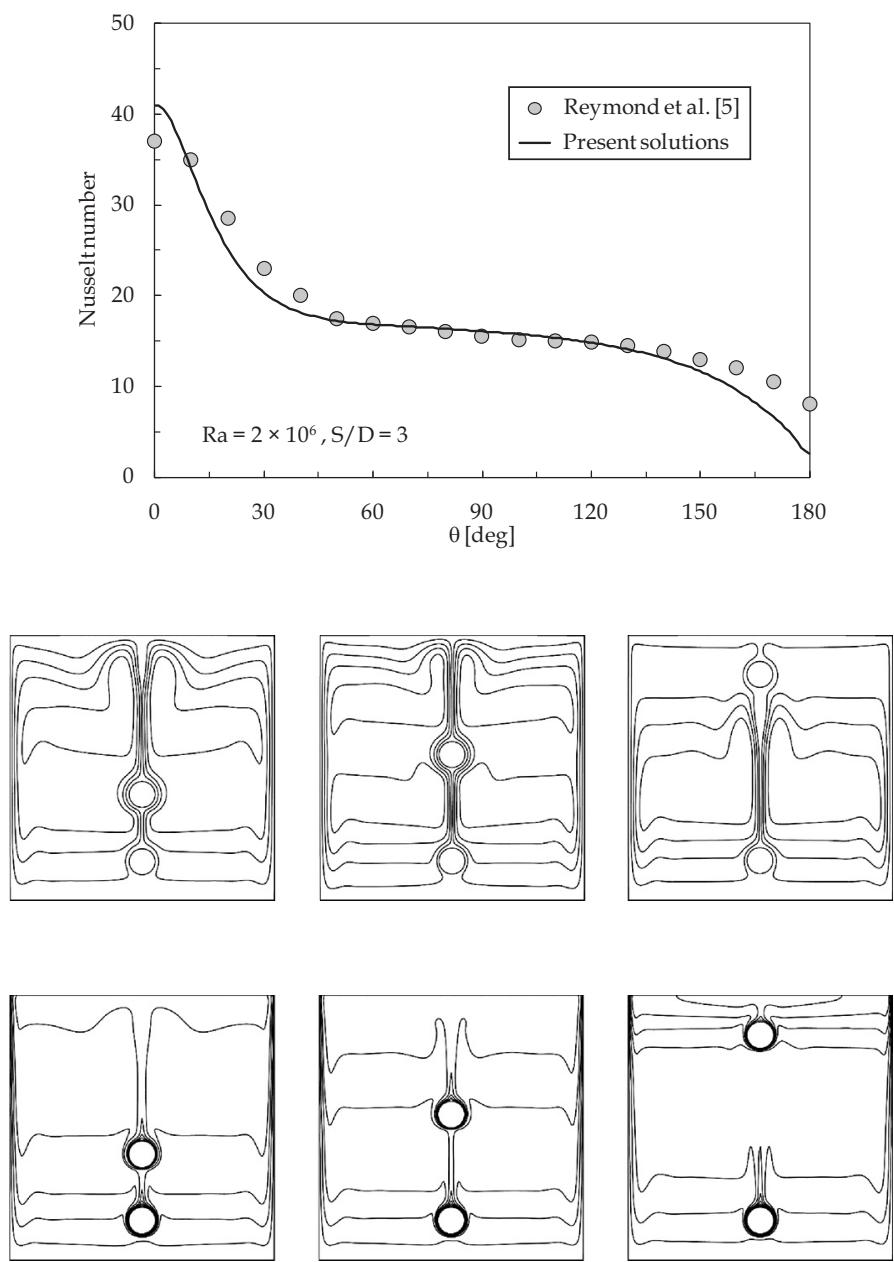


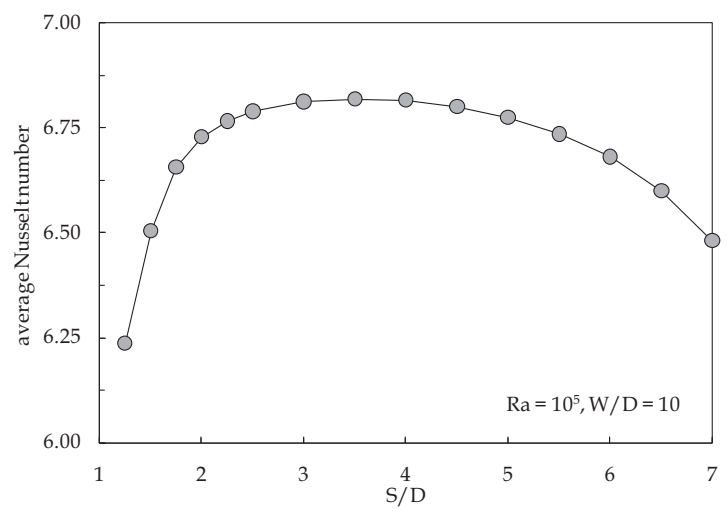

A water-filled rectangular enclosure

2617

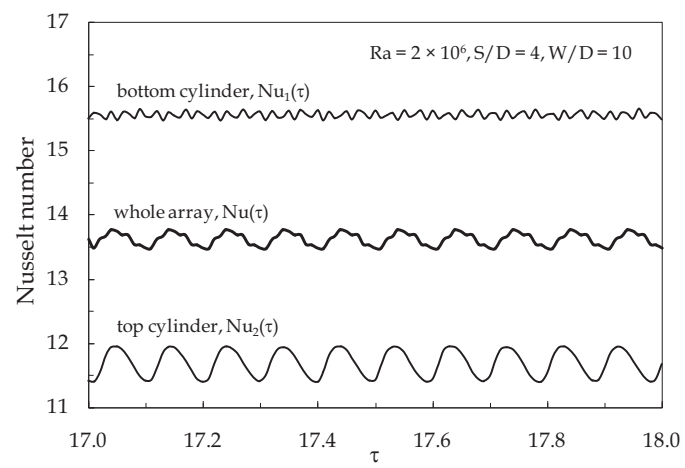

Figure 6.

Asymptotic timedistributions of $\mathrm{Nu}_{1}(\tau), \mathrm{Nu}_{2}(\tau)$ and $\mathrm{Nu}$

$(\tau)$ for $\mathrm{Ra}=2 \times 10^{6}$, $\mathrm{S} / \mathrm{D}=4$ and $\mathrm{W} / \mathrm{D}=10$

$\mathrm{W} / \mathrm{D}=10$. The corresponding asymptotic time-evolution of the isotherm contour plots is documented in Figure 7 by the way of six snapshots covering one full period of oscillation, showing that the plumes generated by both cylinders sway back and forth periodically, which is the reason of the oscillatory patterns detected for $\mathrm{Nu}_{1}$ and $\mathrm{Nu}_{2}$ and then $\mathrm{Nu}$. The effect of the inter-cylinder spacing on the periodicity of the asymptotic solution is illustrated in Figure 8, in which the time-distribution of the average Nusselt number of the whole array and the related phase-space trajectory displayed in terms of $\mathrm{dNu}(\tau) / \mathrm{d} \tau \mathrm{vs}$ $\mathrm{Nu}(\tau)$, as well as the Fourier frequency spectrum of the heat transfer performance of each cylinder, displayed in terms of $\left(\mathrm{Nu}_{\max }-\mathrm{Nu}_{\min }\right)$ vs $\mathrm{F}$, where $\mathrm{F}$ is the dimensionless frequency of oscillation equal to the inverse of the dimensionless period of oscillation $\Omega$, are reported for four different values of S/D. It can be seen that the amplitude of oscillation of the heat transfer performance of the top cylinder decreases as the top cylinder approaches the top wall of the cavity, which increasingly limits the swaying of the plume generated by the cylinder. In contrast, provided that the inter-cylinder spacing is not too small, the plume spawned by the bottom cylinder is barely affected by the distance of the downstream cylinder, as reflected by the constant amplitude of oscillation of its average Nusselt number. Moreover, it is apparent that the average Nusselt number of the whole array has a peak at an intermediate inter-cylinder spacing, for the same reasons discussed earlier for $\mathrm{Ra}=10^{5}$. 


\section{HFF \\ 30,5}

\section{8}

\section{Figure 7.}

Asymptotic timeevolution of the isotherm contours during one period of oscillation for $\mathrm{Ra}=$ $2 \times 10^{6}, \mathrm{~S} / \mathrm{D}=4$ and $\mathrm{W} / \mathrm{D}=10$

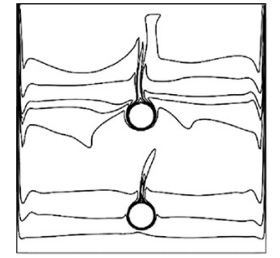

(a)

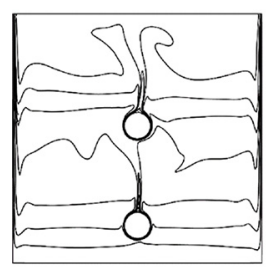

(d)

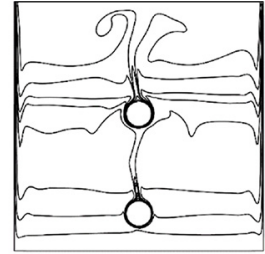

(b)

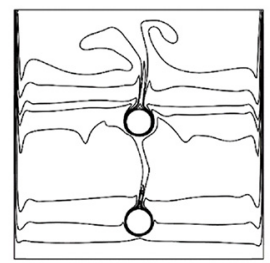

(e)

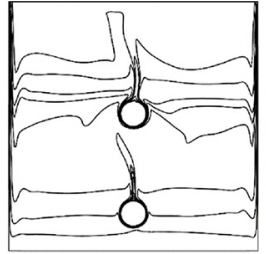

(c)

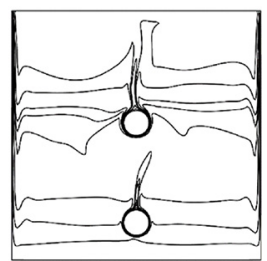

(f)

Notes: (a) $\tau=17.67$; (b) $\tau=17.72$; (c) $\tau=17.78$; (d) $\tau=17.80$; (e) $\tau=17.82$; (f) $\tau=17.87$

As far as the role played by the cavity width is concerned, a selection of local results are displayed in Figures 9 and 10, in which steady-state streamline and isotherm contours, relative to five different cavity widths, are plotted for $\mathrm{Ra}=10^{5}$ and $\mathrm{S} / \mathrm{D}=3$. The related distribution of the average Nusselt number of the cylinder array, $\mathrm{Nu}$, is depicted in Figure 11. It can be noticed that the thermal performance remains substantially the same as the cavity width is decreased, unless the gap between the cylinders and the sidewalls becomes small enough not to allow the development of two distinguished uprising and descending boundary layers. In such a case, two counter-rotating cells develop above each cylinder, with a consequent reduction in the amount of heat transferred from the cylinders. However, further decrease of the cavity width gives rise to a significant compression of the isotherms between the cylinders and the sidewalls, thus implying a notable enhancement of the local, and then the overall, heat transfer rate. Obviously, as the boundary layer thickness decreases with an increase in the Rayleigh number, the cavity width corresponding to the minimum heat transfer performance decreases as the Rayleigh number is increased, as shown in Figure 12, where the distribution of the average Nusselt number of the whole array normalized using the average Nusselt number computed for $\mathrm{W} / \mathrm{D}=15$, denoted as $\mathrm{Nu} / \mathrm{Nu}_{15}$, are plotted vs $\mathrm{W} / \mathrm{D}$ for $\mathrm{S} / \mathrm{D}=3$ using Ra as a parameter.

Finally, the effect of the cavity width on the periodicity of the asymptotic solutions found at high Rayleigh numbers is displayed in Figure 13, in which the time-distribution of the average Nusselt number of the whole array and the related phase-space trajectory, as well as the Fourier frequency spectrum of the heat transfer performance of each cylinder, are reported for four different values of W/D, showing that, owing to the confinement role played by the sidewalls, the amplitude of oscillation of the heat transfer performance of the top cylinder decreases up to vanishing as the cavity width is reduced. Conversely, the heat transfer rate at the 

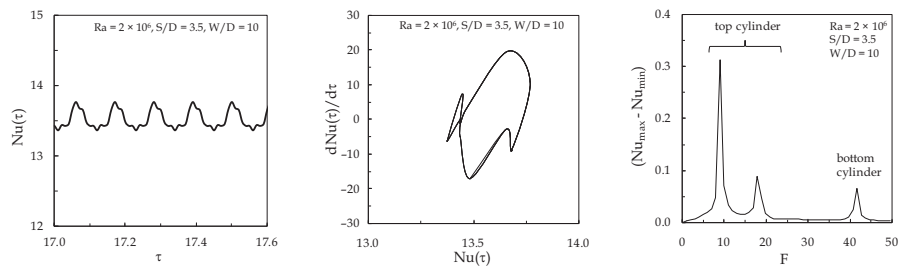

A water-filled rectangular enclosure
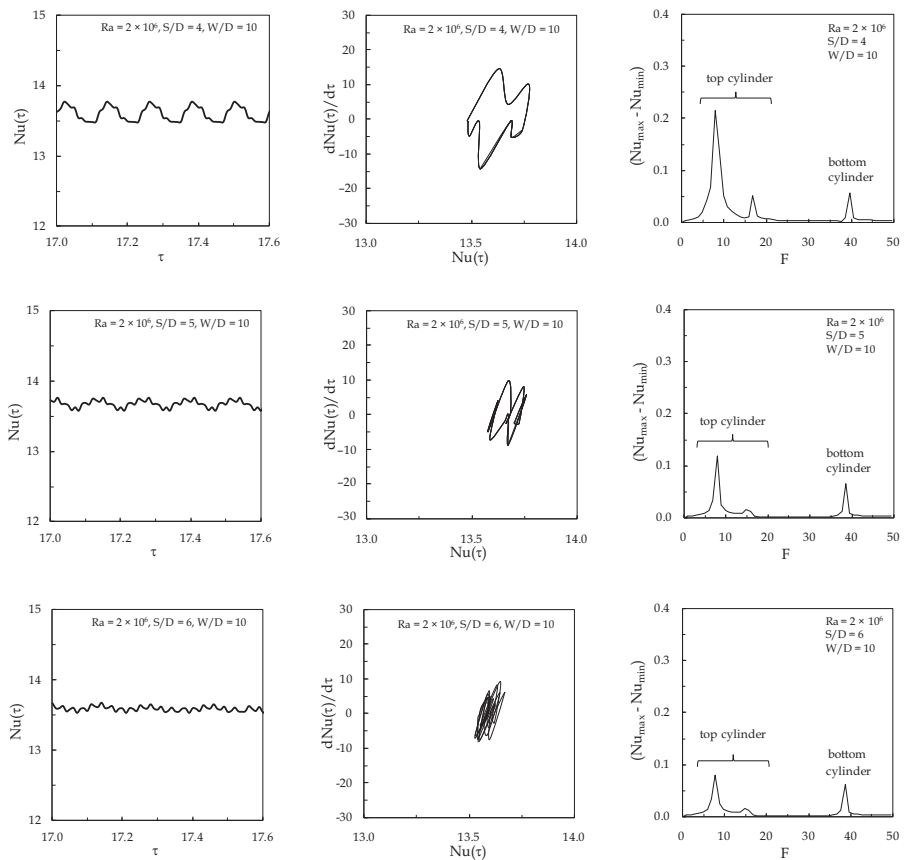

2619

Figure 8.

Asymptotic timedistributions, phase -space trajectories and

Fourier frequency spectra of $\mathrm{Nu}(\tau)$ for $\mathrm{Ra}=2 \times 10^{6}$, $\mathrm{W} / \mathrm{D}=10$ and $\mathrm{S} /$ $\mathrm{D}=3.5$ 4, 5 and 6
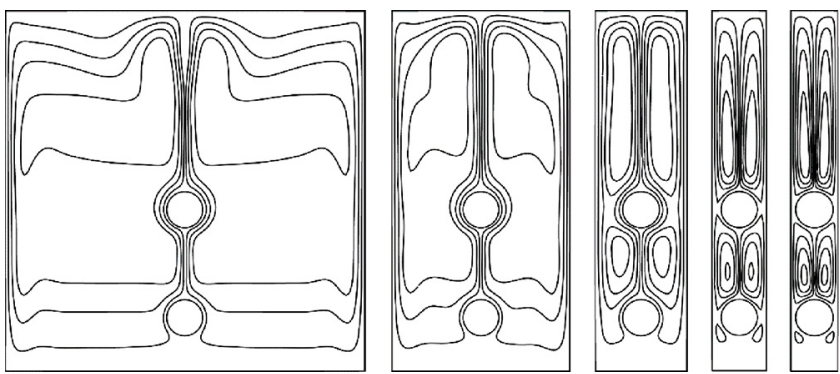

Figure 9.

Steady-state streamline contours for $\mathrm{Ra}=10^{5}, \mathrm{~S} / \mathrm{D}=3$ and $\mathrm{W} / \mathrm{D}=10,5,2.5$,

1.5 and 1.25

bottom cylinder tends to remain somehow periodic, with very small amplitudes of oscillation, which can tentatively be ascribed to the destabilization effect suffered by the plume at its impingement upon the heated surface of the downstream cylinder. 
HFF

30,5

\section{Conclusions}

Laminar natural convection from a pair of heated horizontal cylinders set one above the other inside a water-filled rectangular enclosure has been studied numerically using a control-volume formulation of the finite-difference method based on the SIMPLE-C algorithm and a composite polar/Cartesian discretization grid scheme.

\section{0}

Figure 10.

Steady-state isotherm contours for $\mathrm{Ra}=$ $10^{5}, \mathrm{~S} / \mathrm{D}=3$ and $\mathrm{W} / \mathrm{D}=10,5,2.5$, 1.5 and 1.25
Figure 11.

Distribution of Nu vs $\mathrm{W} / \mathrm{D}$ for $\mathrm{Ra}=10^{5}$ and $\mathrm{S} / \mathrm{D}=3$
Figure 12.

Distributions of $\mathrm{Nu} / \mathrm{Nu}_{15}$ vs W/D for $\mathrm{S} / \mathrm{D}=3$ and $\mathrm{Ra}=10^{4}$, $10^{5}$ and $10^{6}$
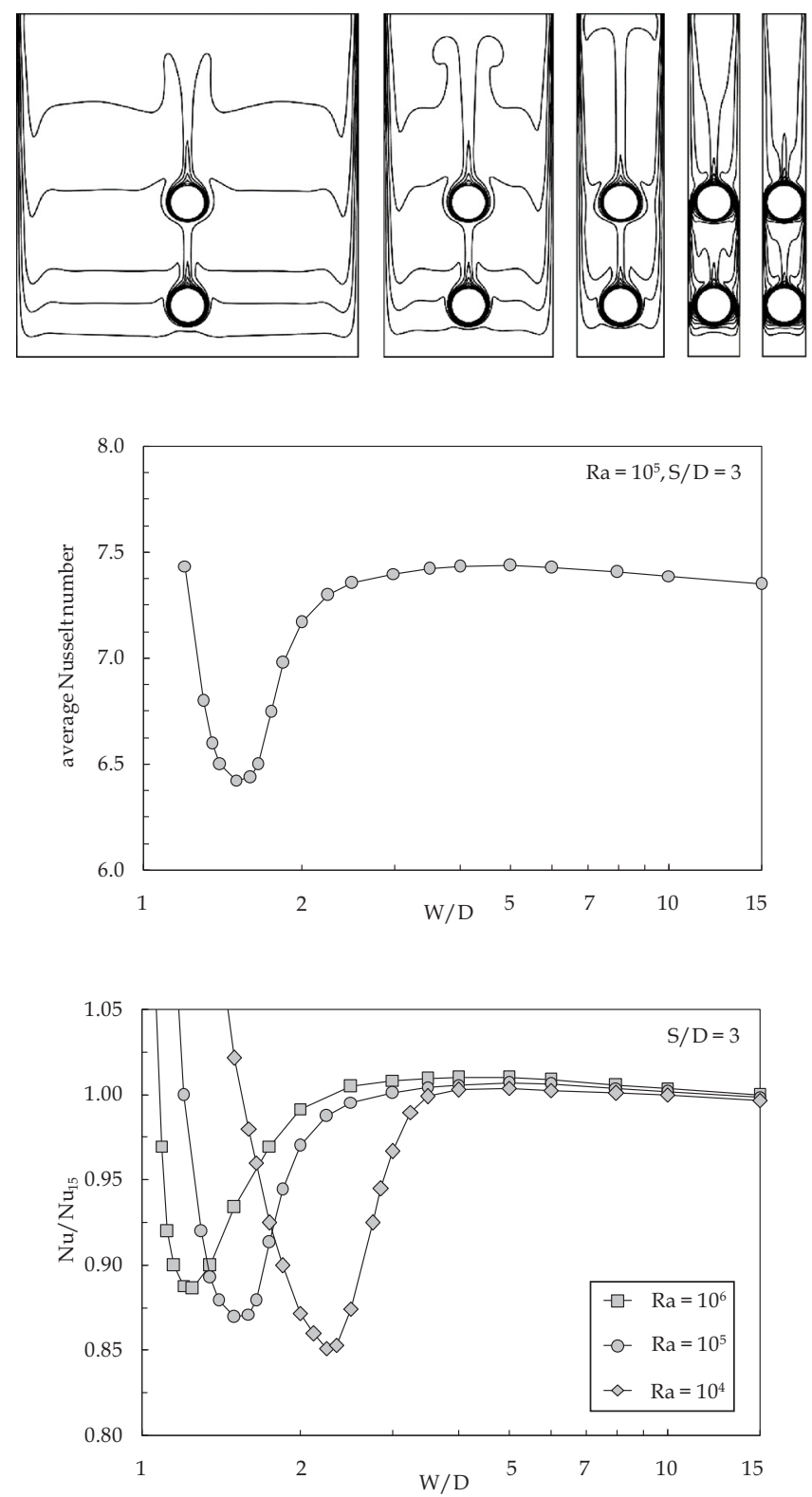

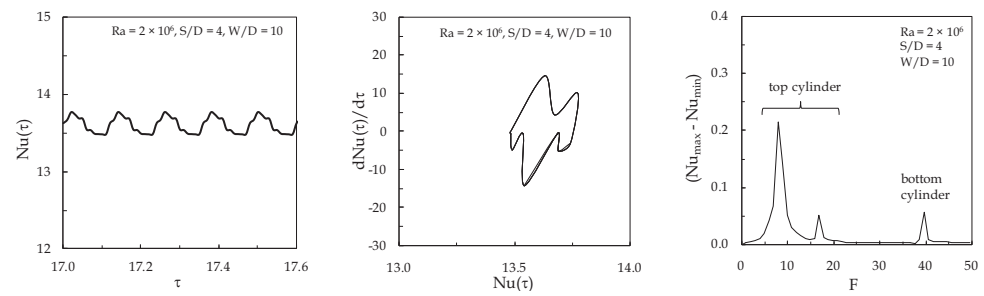

A water-filled rectangular enclosure
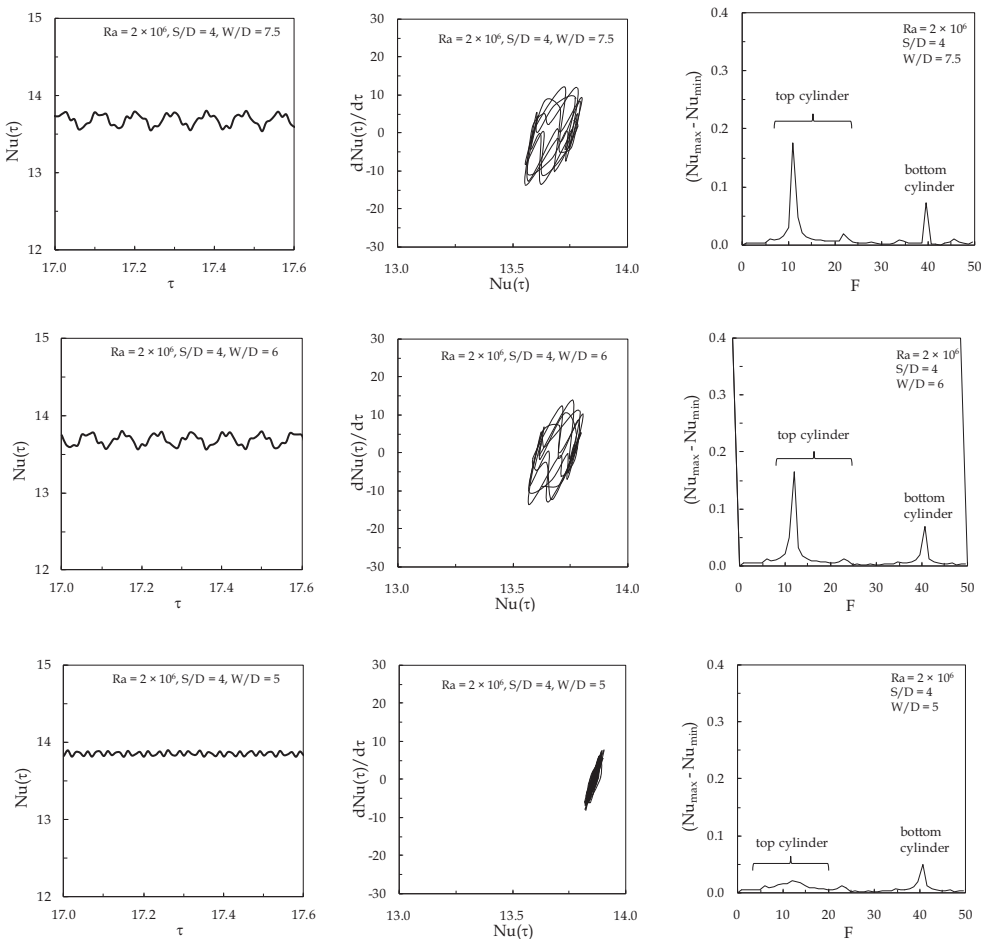

Figure 13. Asymptotic timedistributions, phasespace trajectories and

Fourier frequency spectra of $\mathrm{Nu}(\tau)$ for $\mathrm{Ra}=2 \times 10^{6}, \mathrm{~S} / \mathrm{D}=4$ and $\mathrm{W} / \mathrm{D}=10,7.5,6$ and 5

The main results obtained in the present study may be summarized as follows:

- The existence of an optimum cylinder spacing for maximum heat transfer rate has been found at any investigated Rayleigh number.

- As a consequence of the downstream confinement, a periodic flow arises at sufficiently high Rayleigh numbers.

- The amplitude of oscillation of the periodic heat transfer performance of the cylinder array decreases as the cylinder spacing is increased and the cavity width is decreased, whereas the frequency of oscillations remains almost the same.

- At very small cavity widths, a transition from the typical two-cell flow pattern to a four-cell flow pattern occurs. 


\section{References}

Atmane, M.A., Chan, V.S.S. and Murray, D.B. (2003), "Natural convection around a horizontal heated cylinder: the effect of vertical confinement", International Journal of Heat and Mass Transfer, Vol. 46 No. 19, pp. 3661-3672.

Chae, M. and Chung, B. (2011), "Effect of pitch-to-diameter ratio on the natural convection heat transfer of two vertically aligned horizontal cylinders", Chemical Engineering Science, Vol. 66 No. 21, 2622 pp. 5321-5329.

Corcione, M. (2005), "Correlating equations for free convection heat transfer from horizontal isothermal cylinders set in a vertical array", International Journal of Heat and Mass Transfer, Vol. 48 No. 17, pp. 3660-3673.

Fiscaletti, D., Angeli, D., Tarozzi, L. and Barozzi, G.S. (2013), "Buoyancy-induced transitional flows around an enclosed horizontal cylinder: an experiment", International Journal of Heat and Mass Transfer, Vol. 58 Nos 1/2, pp. 619-631.

Gebhart, B., Pera, L. and Schorr, A.W. (1970), "Steady laminar natural convection plumes above a horizontal line heat source", Interntional Journal of Heat and Mass Transfer, Vol. 13 No. 1, pp. 161-171.

Grafsronningen, S. and Jensen, A. (2012), "Natural convection heat transfer from two horizontal cylinders at high Rayleigh numbers", International Journal of Heat and Mass Transfer, Vol. 55, pp. 552-5564.

Grafsrønningen, S. and Jensen, A. (2013), "Natural convection heat transfer from three vertically arranged horizontal cylinders with dissimilar separation distance at moderately high Rayleigh numbers", International Journal of Heat and Mass Transfer, Vol. 57 No. 2, pp. 519-527.

Heo, J. and Chung, B. (2014), "Natural convection of two staggered cylinders for various prandtl numbers and vertical and horizontal pitches", Heat and Mass Transfer, Vol. 50 No. 6, pp. 769-777.

Heo, J., Chae, M. and Chung, B. (2013), "Influences of vertical and horizontal pitches on the natural convection of two staggered cylinders", International Journal of Heat and Mass Transfer, Vol. 57 No. 1, pp. 1-8.

Incropera, F.P. and Yaghoubi, M.A. (1980), "Buoyancy driven flows originating from heated cylinders submerged in a finite water layer", International Journal of Heat and Mass Transfer, Vol. 23 No. 3, pp. 269-278.

Kuehn, T.H. and Goldstein, R.J. (1976), "Correlating equations for natural convection heat transfer between horizontal circular cylinders", International Journal of Heat and Mass Transfer, Vol. 19 No. 10, pp. 1127-1134.

Kuehn, T.H. and Goldstein, R.J. (1980), "Numerical solution to the Navier-Stokes equations for laminar natural convection about a horizontal isothermal circular cylinder", International Journal of Heat and Mass Transfer, Vol. 23 No. 7, pp. 971-979.

Kuehner, J.P., Pflug, J.R., Tessier, F.A., Jr, Hamed, A.M. and Moiso Marin, F.J. (2012), "Velocity measurements in the free convection flow above a heated horizontal cylinder", Int. J. of Heat and Mass Transfer, Vol. 55 Nos 17/18, pp. 4711-4723.

Leonard, B.P. (1979), "A stable and accurate convective modelling procedure based on quadratic upstream interpolation", Computer Methods in Applied Mechanics and Engineering, Vol. 19 No. 1, pp. 59-78.

Marsters, G.F. (1972), "Arrays of heated horizontal cylinders in natural convection”, International Journal of Heat and Mass Transfer, Vol. 15 No. 5, pp. 921-933.

Patankar, S.V. and Spalding, D.B. (1972), "A calculation procedure for heat, mass and momentum transfer in three-dimensional parabolic flows", International Journal of Heat and Mass Transfer, Vol. 15 No. 10, pp. 1787-1797. 
Persoons, T., O’Gorman, I.M., Donoghue, D.B., Byrne, G. and Murray, D.B. (2011), "Natural convection heat transfer and fluid dynamics for a pair of vertically aligned isothermal horizontal cylinders", International Journal of Heat and Mass Transfer, Vol. 54, pp. 5163-5172.

Raithby, G.D and Hollands, K.G.T. (1976), "Laminar and turbulent free convection from elliptic cylinders with a vertical plate and horizontal circular cylinder as special cases", Journal of Heat Transfer, Vol. 98 No. 1, pp. 72-80.

Reymond, O., Murray, D.B. and O'Donovan, T.S. (2008), "Natural convection heat transfer from two horizontal cylinders", Experimental Thermal and Fluid Science, Vol. 32 No. 8, pp. 1702-1709.

Sadegh Sadeghipour, M. and Asheghi, M. (1994), "Free convection heat transfer from arrays of vertically separated horizontal cylinders at low Rayleigh numbers", International Journal of Heat and Mass Transfer, Vol. 37 No. 1, pp. 103-109.

Saitoh, T., Sajiki, T. and Maruhara, K. (1993), "Bench mark solutions to natural convection heat transfer problem around a horizontal circular cylinder", International Journal of Heat and Mass Transfer, Vol. 36 No. 5, pp. 1251-1259.

Shyam, R., Sasmal, C. and Chhabra, R.P. (2013), "Natural convection heat transfer from two vertically aligned circular cylinders in power-law fluids", International Journal of Heat and Mass Transfer, Vol. 64, pp. 1127-1152.

Sparrow, E.M. and Boessneck, D.S. (1983), "Effect of traverse misalignment on natural convection from a pair of parallel, vertically stacked, horizontal cylinders", Journal of Heat Transfer, Vol. 105 No. 2, pp. 241-247.

Sparrow, E.M. and Niethammer, J.E. (1981), "Effect of vertical separation distance and cylinder-tocylinder temperature imbalance on natural convection from a pair of vertical cylinders", Journal of Heat Transfer, Vol. 103 No. 4, pp. 638-644.

Tokura, I., Saito H., Kishinami, K. and Muramoto, K. (1983) "An experimental study of free convection heat transfer from a horizontal cylinder in a vertical array set in free space between parallel walls", Journal of Heat Transfer, Vol. 105 No. 1, pp. 102-107.

Van Doormaal, J.P. and Raithby, G.D. (1984), "Enhancements of the simple method for predicting incompressible fluid flows", Numerical Heat Transfer, Vol. 11, pp. 147-163.

Wang, P., Kahawita, R. and Nguyen, T.H. (1990), "Numerical computation of the natural convection flow about a horizontal cylinder using splines", Numerical Heat Transfer, Vol. 17 No. 2, pp. 191-215.

\section{Corresponding author}

Massimo Corcione can be contacted at: massimo.corcione@uniroma1.it
A water-filled rectangular enclosure

2623

For instructions on how to order reprints of this article, please visit our website:

www.emeraldgrouppublishing.com/licensing/reprints.htm

Or contact us for further details: permissions@emeraldinsight.com 
Reproduced with permission of copyright owner. Further reproduction prohibited without permission. 